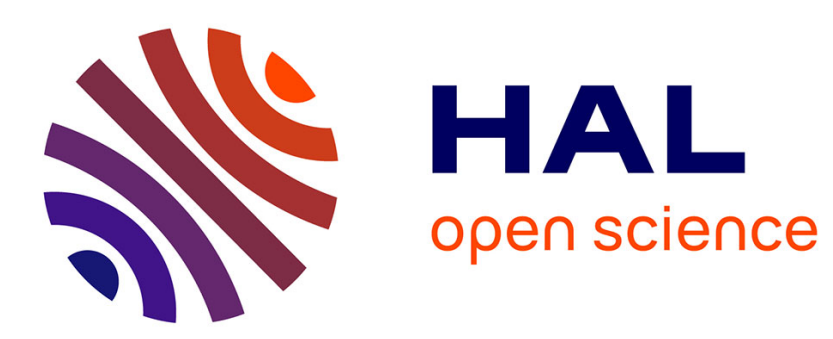

\title{
Interest rate rules, inflation and the Taylor principle: An analytical exploration
}

\author{
Jean-Pascal Bénassy
}

\section{To cite this version:}

Jean-Pascal Bénassy. Interest rate rules, inflation and the Taylor principle: An analytical exploration. 2005. halshs-00590564

\section{HAL Id: halshs-00590564 https://shs.hal.science/halshs-00590564}

Preprint submitted on 3 May 2011

HAL is a multi-disciplinary open access archive for the deposit and dissemination of scientific research documents, whether they are published or not. The documents may come from teaching and research institutions in France or abroad, or from public or private research centers.
L'archive ouverte pluridisciplinaire HAL, est destinée au dépôt et à la diffusion de documents scientifiques de niveau recherche, publiés ou non, émanant des établissements d'enseignement et de recherche français ou étrangers, des laboratoires publics ou privés. 
WORKING PAPER № 2005 - 46

Interest rate rules, inflation and the Taylor principle:

An analytical exploration

Jean-Pascal Bénassy

JEL Codes : E5, E52, E58

Keywords : Taylor principle, interest rate rules, Taylor rules, inflation, optimal monetary policy 


\title{
Interest Rate Rules, Inflation and the Taylor Principle: An Analytical Exploration
}

\author{
Jean-Pascal Bénassy *† \\ PSE and CEPREMAP \\ September 2003 \\ Revised July 2004
}

\begin{abstract}
The purpose of this article is to characterize optimal interest rate rules in the framework of a dynamic stochastic general equilibrium model, and notably to scrutinize the "Taylor principle", according to which the nominal interest rate should respond more than one for one to inflation. This model yields explicit solutions for the optimal rule. We find that the elasticity of response depends on numerous factors, such as the degree of price rigidity, the autocorrelation of the underlying shocks, or which measure of inflation is used. In general the optimal elasticity of the interest rate with respect to inflation needs not be greater than one.
\end{abstract}

${ }^{*}$ I wish to thank Daniel Laskar and an anonymous referee for their perceptive comments on earlier drafts of this paper. Of course all remaining deficiencies are mine.

${ }^{\dagger}$ Address: CEPREMAP-ENS, 48 Boulevard Jourdan, Bâtiment E, 75014, Paris, France. Telephone: 33-1-43136338. Fax: 33-1-43136232. E-mail: benassy@pse.ens.fr 


\section{Introduction}

The purpose of this article is to characterize optimal interest rate rules in the framework of a dynamic stochastic general equilibrium model, and notably to examine the much debated subject of how nominal interest rates should react to inflation.

Indeed following Taylor's (1993) influential article, many authors have studied interest rate rules where central bank policy is a function of endogenous variables such as inflation and output. A particularly scrutinized issue has been the response to inflation", and notably the "Taylor principle", according to which the nominal interest rate should respond more than one for one to inflation ${ }^{2}$. In a nutshell, if the interest rate rule is of the form (omitting constants) $i_{t}=\gamma \pi_{t}$, then the Taylor principle says that $\gamma$ should be greater than 1.

The basic framework we shall use for this investigation is that of a dynamic monetary economy subject to stochastic shocks, like productivity shocks. We shall develop a simple model for which we will be able to compute explicit solutions for the optimal interest rate ules $^{3}$. The optimal interest rate policy is obtained through maximization of households' utility, subject to the laws of motion of the economy. In such a framework, and under rational expectations, the natural expression of optimal interest rules would be a function linking the interest rate to all observable shocks.

But, as indicated above, our main interest will be in rules expressed as a function of inflation, and in examining the size of their elasticity of response. We can identify two channels through which inflation enters the response function, which we will call "intrinsic" and "surrogate".

(a) The "intrinsic" channel actually concerns not current inflation but expected inflation, for the following natural reason: expected inflation appears in the households's demand functions, and therefore in the dynamic

${ }^{1}$ The original Taylor contribution introduced both inflation and output as arguments of the interest rate rule, but in subsequent writings the role of output has been overshadowed by that of inflation.

${ }^{2}$ There are actually two different aspects of the Taylor principle in the literature. The first, which is the subject of this paper, is concerned with the optimal response of the interest rate to inflation. The second one says that it is necessary to respect the Taylor principle to obtain price determinacy. The validity of that claim in non-Ricardian frameworks has been analyzed in Bénassy (2002b).

${ }^{3}$ There are already in the literature numerous contributions deriving optimal rules from explicit maximization, for example Rotemberg and Woodford (1997, 1999), Svensson (1997, 1999), Clarida, Gali and Gertler (1999), King and Wolman (1999), Erceg, Henderson and Levin (2000), Henderson and Kim (2001), Woodford (2003). Due to the complexity of calculations many contributions use numerical simulations or quadratic approximations. 
equations of the economy. Consequently it will also generally appear in the optimal interest rate rules.

(b) The second way inflation appears in the interest rate rules is as a "surrogate" for the underlying shocks when these are omitted from the policy function. In that respect, the argument of the function can be either expected inflation or current inflation (it could even be some past inflation).

So, in order to investigate the optimal response of interest rates to inflation, we shall derive a number of optimal interest rate rules taking into account the two above channels.

In order to disentangle them, we shall first derive an optimal interest rate rule when both expected inflation and shocks appear independently as arguments.

We shall then derive, in the tradition of dynamic stochastic general equilibrium (DSGE) models, interest rate rules that respond to shocks only. This will show that the optimal response to shocks depends on the nature of the underlying nominal rigidities ${ }^{4}$.

Finally we shall investigate, for various types of rigidities, a number of interest rate rules where current or expected inflation act as surrogates for the underlying shocks. We shall see that the optimal degree of response to inflation depends on numerous factors, like which measure of inflation (current or expected) is used, the nature and degree of price rigidities, and the autocorrelation of shocks. But we will find that the corresponding elasticity can be smaller or greater than one, depending on the values of the relevant parameters, and thus not systematically greater than one.

\section{The model}

\subsection{The agents}

We shall consider a monetary overlapping generations model (Samuelson, 1958) with production. The economy includes representative firms and households, and the government.

Households of generation $t$ live for two periods, work $N_{t}$ and consume $C_{1 t}$ in period $t$, consume $C_{2 t+1}$ in period $t+1$. They maximize the expected value of the following two period utility:

$$
U_{t}=\alpha \frac{C_{1 t}^{1-\sigma}}{1-\sigma}+\frac{C_{2 t+1}^{1-\sigma}}{1-\sigma}-N_{t} \quad \sigma \geq 0
$$

\footnotetext{
${ }^{4}$ We shall notably study Walrasian prices and wages, preset prices and preset wages.
} 
Households are submitted in each period of their life to a "cash in advance" constraint:

$$
M_{1 t} \geq P_{t} C_{1 t} \quad M_{2 t+1} \geq P_{t+1} C_{2 t+1}
$$

The total quantity of money is $M_{t}=M_{1 t}+M_{2 t}$. Since the young household starts his life without any asset, he has to borrow $P_{t} C_{1 t}$ from the bank at the interest rate $i_{t}$ in order to satisfy the cash in advance constraint. Consequently the bank makes profits $\Lambda_{t}$, equal to:

$$
\Lambda_{t}=i_{t} P_{t} C_{1 t}
$$

To simplify calculations we assume that these profits $\Lambda_{t}$ are redistributed lump-sum to the young households ${ }^{5}$.

The representative firm in period $t$ produces output $Y_{t}$ with labor $N_{t}$ via the production function:

$$
Y_{t}=Z_{t} N_{t}
$$

where $Z_{t}$ is a technological shock common to all firms. We assume that the firms belong to the young households, to which they distribute their profits, if any.

\subsection{Government policy and the optimality criterion}

The government has essentially one policy instrument, the nominal interest rate $i_{t}$.

In order to evaluate the optimality properties of potential interest rate policies, we shall use the criterion proposed by Samuelson for the overlapping generations model (Samuelson, 1967, 1968, Abel 1987) and assume that in period $t$ the government maximizes the function $V_{t}$ :

$$
V_{t}=E_{t} \sum_{s=t-1}^{\infty} \beta^{s-t} U_{s}
$$

The sum starts at $s=t-1$ because the old household born in $t-1$ is still alive in $t$. Rearranging the terms in the infinite sum (5), we find that, up to a constant, the criterion $V_{t}$ can be rewritten under the more convenient form:

\footnotetext{
${ }^{5}$ This assumption simplifies notably the asset dynamics (see equation 15 below). It is conjectured that the main results would still hold under alternative redistribution schemes, although explicit solutions might not be available throughout.
} 


$$
V_{t}=E_{t} \sum_{s=t}^{\infty} \beta^{s-t} \Delta_{s}
$$

with:

$$
\Delta_{t}=\alpha \frac{C_{1 t}^{1-\sigma}}{1-\sigma}+\frac{1}{\beta} \frac{C_{2 t}^{1-\sigma}}{1-\sigma}-N_{t}
$$

\section{Market equilibrium}

For the policy evaluations that will follow, we need to characterize the market equilibrium.

Consider first the problem of the old households in period $t$. We denote by $\Omega_{t-1}$ the financial wealth that the old households have accumulated at the end of period $t-1$, and which they own at the beginning of period $t$. With a hundred percent cash in advance constraint (formula 2), their consumption $C_{2 t}$ is simply given by:

$$
P_{t} C_{2 t}=\Omega_{t-1}
$$

Now let us write the maximization program of the young household born in $t$. When young, the representative household receives wages $W_{t} N_{t}$, firms' profits $\Psi_{t}=P_{t} Y_{t}-W_{t} N_{t}$ and central bank profits $\Lambda_{t}$. If he consumes $C_{1 t}$ in the first period of his life, he will have accumulated at the end of period $t$ a financial wealth:

$$
\Omega_{t}=\left(W_{t} N_{t}+\Psi_{t}+\Lambda_{t}\right)-\left(1+i_{t}\right) P_{t} C_{1 t}
$$

In view of (8), the part of the household's expected utility that pertains to his second period consumption can be written:

$$
E_{t}\left(\frac{C_{2 t+1}^{1-\sigma}}{1-\sigma}\right)=\frac{\Omega_{t}^{1-\sigma}}{1-\sigma} E_{t}\left(\frac{1}{P_{t+1}}\right)^{1-\sigma}
$$

where the term $E_{t}\left(1 / P_{t+1}\right)^{1-\sigma}$ represents young households' expectations. Note that, although we will assume rational expectations in all that follows, this term could possibly differ from its rational expectations value, for example if households were involved in an ongoing learning process ${ }^{6}$.

So the expected utility maximization program of the young household boils down to choosing $C_{1 t}$ and $N_{t}$ so as to solve:

\footnotetext{
${ }^{6}$ One may find explicit analysis of such a learning process in a similar context in Bullard and Mitra (2002) and Evans and Honkapohja (2003).
} 


$$
\begin{gathered}
\text { Maximize } \alpha \frac{C_{1 t}^{1-\sigma}}{1-\sigma}+\frac{\Omega_{t}^{1-\sigma}}{1-\sigma} E_{t}\left(\frac{1}{P_{t+1}}\right)^{1-\sigma}-N_{t} \quad \text { s.t. } \\
\Omega_{t}=\left(W_{t} N_{t}+\Psi_{t}+\Lambda_{t}\right)-\left(1+i_{t}\right) P_{t} C_{1 t}
\end{gathered}
$$

The first order conditions with respect to $C_{1 t}$ and $N_{t}$ are:

$$
\begin{aligned}
\alpha C_{1 t}^{-\sigma} & =\left(1+i_{t}\right) P_{t} \Omega_{t}^{-\sigma} E_{t}\left(\frac{1}{P_{t+1}}\right)^{1-\sigma} \\
1 & =W_{t} \Omega_{t}^{-\sigma} E_{t}\left(\frac{1}{P_{t+1}}\right)^{1-\sigma}
\end{aligned}
$$

We have two other equilibrium equations. The first says that total consumption must equal production:

$$
C_{1 t}+C_{2 t}=Y_{t}=Z_{t} N_{t}
$$

The second says that the price is equal to marginal cost:

$$
P_{t}=\frac{W_{t}}{Z_{t}}
$$

We should finally note that, since central bank profits $\Lambda_{t}$ are redistributed to the consumers, $\Omega_{t}$ will remain constant in time. Indeed, combining (3), (8), (9) and (13), we obtain:

$$
\Omega_{t}=P_{t} Y_{t}-\left(1+i_{t}\right) P_{t} C_{1 t}+\Lambda_{t}=P_{t} C_{2 t}=\Omega_{t-1}=\Omega
$$

We can also combine (12) and (14) to find the dynamic equation giving Walrasian prices, denoted as $P_{t}^{*}$ :

$$
\frac{1}{P_{t}^{*}}=Z_{t} \Omega^{-\sigma} E_{t}\left(\frac{1}{P_{t+1}^{*}}\right)^{1-\sigma}
$$

A solution to this dynamic equation is derived in appendix 1 . We note that Walrasian prices do not depend on the interest rate.

We will further make the traditional assumption that a higher expected inflation leads to a higher current equilibrium price, which leads to the following restriction on $\sigma$ :

$$
0 \leq \sigma \leq 1
$$




\section{Optimal interest policy: the Walrasian case}

As a benchmark, we shall now compute the optimal interest rate policy in the case where all markets clear.

Proposition 1: Under Walrasian prices and wages the optimal interest rate rule is:

$$
i_{t}=0
$$

Proof: The central bank must choose the interest rate so as to maximize, in each period and for each value of the shocks:

$$
\Delta_{t}=\alpha \frac{C_{1 t}^{1-\sigma}}{1-\sigma}+\frac{1}{\beta} \frac{C_{2 t}^{1-\sigma}}{1-\sigma}-N_{t}
$$

or, using (13):

$$
\Delta_{t}=\alpha \frac{C_{1 t}^{1-\sigma}}{1-\sigma}+\frac{1}{\beta} \frac{C_{2 t}^{1-\sigma}}{1-\sigma}-\frac{C_{1 t}+C_{2 t}}{Z_{t}}
$$

We first note that $C_{2 t}$ (equation 8) does not depend on the interest rate, since $P_{t}^{*}$ does not. Combining (11), (12) and (14) we find that $C_{1 t}$ is given by:

$$
C_{1 t}=\left(\frac{\alpha Z_{t}}{1+i_{t}}\right)^{1 / \sigma}
$$

Inserting this value of $C_{1 t}$ into (20) and maximizing $\Delta_{t}$ with respect to $i_{t}$ yields immediately (18).

Q.E.D.

We see that, in the Walrasian case, no matter what are the shocks or inflationary expectations, the interest rate should remain totally unresponsive. This is actually the famous "Friedman rule" (Friedman, 1969).

So we have here a first example where the interest rate should not respond at all to inflation, and therefore the Taylor principle does not hold.

\section{$5 \quad$ Preset prices}

We will now move to the study of economies with nominal rigidities. We shall begin assuming preset prices $^{7}$, and make the assumption, traditional in the

\footnotetext{
${ }^{7}$ Preset wages are studied in appendix 2 .
} 
literature since Gray (1976), that the preset price is equal to the expected value of the Walrasian price (in logarithms), i.e.:

$$
p_{t}=E_{t-1} p_{t}^{*}
$$

where ${ }^{8} p_{t}=\log P_{t}, p_{t}^{*}=\log P_{t}^{*}$, and $P_{t}^{*}$, the Walrasian price in period $t$, is the solution of the dynamic equilibrium equation (16).

We note that, since the Walrasian price $P_{t}^{*}$ does not depend on the interest rate, the preset price will not depend on it either.

\subsection{Equilibrium conditions}

Since the price is preset, equation (14) does not hold anymore, but the other equilibrium conditions are still valid:

$$
\begin{gathered}
\alpha C_{1 t}^{-\sigma}=\left(1+i_{t}\right) P_{t} \Omega_{t}^{-\sigma} E_{t}\left(\frac{1}{P_{t+1}}\right)^{1-\sigma} \\
1=W_{t} \Omega_{t}^{-\sigma} E_{t}\left(\frac{1}{P_{t+1}}\right)^{1-\sigma} \\
C_{2 t}=\frac{\Omega}{P_{t}}
\end{gathered}
$$

\subsection{The optimal interest rule}

We shall now derive an optimal interest rate rule having as arguments both the shocks and the households' inflationary expectations:

Proposition 2: Under preset prices the optimal interest rate rule is:

$$
\frac{1}{1+i_{t}}=\min \left[1, Z_{t}\left(\frac{\Omega}{P_{t}}\right)^{-\sigma} E_{t}\left(\frac{P_{t}}{P_{t+1}}\right)^{1-\sigma}\right]
$$

Proof: We have to maximize for all values of the shocks the quantity:

$$
\Delta_{t}=\alpha \frac{C_{1 t}^{1-\sigma}}{1-\sigma}+\frac{1}{\beta} \frac{C_{2 t}^{1-\sigma}}{1-\sigma}-\frac{C_{1 t}+C_{2 t}}{Z_{t}}
$$

Now since $P_{t}$ does not depend on $i_{t}$, from (25) $C_{2 t}$ does not either, so that we are left to maximize in $i_{t}$ for all values of the shocks:

\footnotetext{
${ }^{8}$ So in all that follows lowercase letters denote the logarithm of the corresponding uppercase letters.
} 


$$
\alpha \frac{C_{1 t}^{1-\sigma}}{1-\sigma}-\frac{C_{1 t}}{Z_{t}}
$$

where, from formula (23), $C_{1 t}$ is given by:

$$
C_{1 t}=\left[\frac{1+i_{t}}{\alpha} P_{t} \Omega^{-\sigma} E_{t}\left(\frac{1}{P_{t+1}}\right)^{1-\sigma}\right]^{-1 / \sigma}
$$

Let us take $C_{1 t}$ as an intermediate maximization variable. Maximizing (28) we find that the optimal value for $C_{1 t}$ is:

$$
C_{1 t}=\left(\alpha Z_{t}\right)^{1 / \sigma}
$$

Equating the two values (29) and (30), and taking into account the fact that $i_{t}$ must be positive, we find (26).

Q.E.D.

We see that inflationary expectations enter with an elasticity $1-\sigma$, which is always smaller than $1^{9}$. The intuition is simple: since the optimal value of $C_{1 t}$ (equation 30) does not depend on expectations, the optimal interest rate will be chosen so as to exactly neutralize these expectations (formula 29).

\subsection{The interest rate rule and shocks}

We shall now express, in the tradition of DSGE models, the interest rate rule as a function of shocks only. Let us assume the following process for the technology shocks $z_{t}=\log Z_{t}$ :

$$
z_{t}=\frac{u_{t}}{1-\rho L}
$$

where $L$ is the lag operator and the stochastic variable $u_{t}$ is normal and i.i.d.

Proposition 3: Under technology shocks (31), the optimal interest rate rule is:

$$
i_{t}=-\frac{u_{t}}{1-(1-\sigma) \rho}
$$

Proof: Formula (26) yields in logarithms, and ignoring irrelevant constants:

\footnotetext{
${ }^{9}$ We should note that this result does not mean that the Taylor principle is not valid, since we consider only expected inflation through the "intrinsic" channel. Sections 6 and 7 study rules which include the "surrogate" channel as well, and where the Taylor principle sometimes holds.
} 


$$
i_{t}=-z_{t}-p_{t}+(1-\sigma) E_{t} p_{t+1}
$$

It is shown in appendix 1 that, with the technology process (31), the Walrasian price $p_{t}^{*}$ is given by (up to a constant):

$$
p_{t}^{*}=-\mu z_{t}
$$

with:

$$
\mu=\frac{1}{1-(1-\sigma) \rho}
$$

Consequently:

$$
p_{t}=E_{t-1} p_{t}^{*}=-\mu E_{t-1} z_{t}
$$

Then formula (33) becomes:

$$
\begin{aligned}
& i_{t}=-z_{t}+\mu E_{t-1} z_{t}-\mu(1-\sigma) E_{t} z_{t+1} \\
& =-\frac{u_{t}}{1-\rho L}+\frac{\mu \rho u_{t-1}}{1-\rho L}-\frac{\mu(1-\sigma) \rho u_{t}}{1-\rho L}
\end{aligned}
$$

which, after simplification, yields (32).

Q.E.D.

We see that, in this simple case, the optimal interest rate is a function of the innovation of the shock only. In section 7 we shall study a more complex pricing scheme where the optimal interest rate depends on all past values of the innovation.

\section{Inflation as a surrogate for shocks}

In proposition 2 (and the similar proposition 7 in appendix 3 on preset wages) we considered an interest rate rule with both expected inflation and shocks as arguments. Propositions 3 and 8 give rules with only shocks as arguments.

We shall now move to interest rate rules that are functions of inflation (current or expected) only, and we shall see that optimal interest rates will depend on inflation simply because inflation acts as a surrogate to shocks.

In order to make that "surrogate" aspect particularly clear, we shall take the particular case $\sigma=1$, i.e. the case where the "intrinsic" coefficient of response to expected inflation is exactly zero (propositions 2 and 7 ). 


\subsection{Equilibrium}

For $\sigma=1$ a number of formulas actually simplify. Notably formula (16) giving the equilibrium price becomes:

$$
P_{t}^{*}=\frac{\Omega}{Z_{t}}
$$

so that:

$$
p_{t}=E_{t-1} p_{t}^{*}=\omega-E_{t-1} z_{t}
$$

with $\omega=\log \Omega$. The values of the preset price equilibrium quantities are:

$$
\begin{gathered}
C_{1 t}=\frac{\alpha \Omega}{\left(1+i_{t}\right) P_{t}} \\
C_{2 t}=\frac{\Omega}{P_{t}} \\
N_{t}=\frac{\alpha \Omega}{\left(1+i_{t}\right) P_{t} Z_{t}}+\frac{\Omega}{P_{t} Z_{t}}
\end{gathered}
$$

\subsection{Utility evaluation}

Setting $\sigma=1$ in equation (7), we find that the "period $t$ utility" $\Delta_{t}$ is now:

$$
\Delta_{t}=\alpha \log C_{1 t}+\frac{1}{\beta} \log C_{2 t}-N_{t}
$$

Inserting into (43) the values in (40), (41) and (42), we obtain the following value for $\Delta_{t}$ :

$$
\Delta_{t}=\alpha \log \left[\frac{\alpha \Omega}{\left(1+i_{t}\right) P_{t}}\right]+\frac{1}{\beta} \log \left(\frac{\Omega}{P_{t}}\right)-\frac{1}{P_{t} Z_{t}}\left(\frac{\alpha \Omega}{1+i_{t}}+\Omega\right)
$$

or, keeping only the terms containing the interest rate:

$$
\Delta_{t}=-\log \left(1+i_{t}\right)-\frac{1}{P_{t} Z_{t}} \frac{\Omega}{1+i_{t}}
$$

We shall find the optimal interest rate rule by maximizing the expected value of $\Delta_{t}$ (equation 45 ) with respect to the parameters of the rule, assuming that the technological process is still given by (31).

As indicated above, we shall consider two different rules, where the interest rate reacts to current or expected inflation. 


\subsection{Current inflation}

We shall first assume that the interest rate is a function of current inflation:

$$
1+i_{t}=A \exp \left(\gamma \pi_{t}\right)=A \exp \left[\gamma\left(p_{t}-p_{t-1}\right)\right]
$$

Proposition 4: Under preset prices and the technology process (31), the optimal interest rate rule is characterized by:

$$
\begin{gathered}
\gamma=0 \\
A=\exp \left(\frac{V}{2}\right) \\
V=1
\end{gathered}
$$

Proof: Appendix 3.

We see that in this case the Taylor principle does not hold since $\gamma=0$. We can now give a simple intuition as to why the coefficient of reaction to inflation $\gamma$ is equal to zero. Let us denote as $i_{t}^{*}$ the "optimal" interest rate derived in proposition 3. With $\sigma=1$ we have:

$$
i_{t}^{*}=-u_{t}
$$

On the other hand we can compute, using formula (36) with $\mu=1$, the expression of current inflation as a function of shocks:

$$
\pi_{t}=p_{t}-p_{t-1}=-E_{t-1} z_{t}+E_{t-2} z_{t-1}=-\frac{\rho(1-L) u_{t-1}}{1-\rho L}
$$

We see that, because prices are preset, inflation is function of past innovations, whereas the optimal interest rate $i_{t}^{*}$ is function of the current innovation $u_{t}$ only. So $\pi_{t}$ and $u_{t}$ are statistically independent, and therefore current inflation $\pi_{t}$ cannot play the role of a surrogate for $u_{t}$. Moreover a nonzero $\gamma$ would only create unwanted "noise", reducing utility. These explain why the optimal $\gamma$ is equal to zero.

\subsection{Expected inflation}

We shall now assume that the interest rate is a function of expected inflation:

$$
1+i_{t}=A \exp \left(\gamma E_{t} \pi_{t+1}\right)=A \exp \left[\gamma E_{t}\left(p_{t+1}-p_{t}\right)\right]
$$


Proposition 5: Under preset prices and the technology process (31), the optimal interest rate rule is characterized by:

$$
\begin{gathered}
\gamma=\frac{1+\rho}{2 \rho} \\
A=\exp \left(\frac{V}{2}\right) \\
V=\frac{1-\rho}{2}
\end{gathered}
$$

Proof: Appendix 4.

We see that this time $\gamma$ is always greater than 1 , and the Taylor principle is always verified. To give an intuition about the value of the coefficient $\gamma$, we can compute the value of expected inflation as a function of shocks:

$$
\begin{gathered}
E_{t} \pi_{t+1}=\pi_{t+1}=p_{t+1}-p_{t}=-E_{t} z_{t+1}+E_{t-1} z_{t} \\
=-\frac{\rho(1-L) u_{t}}{1-\rho L}=-\rho u_{t}+\frac{\rho(1-\rho) u_{t-1}}{1-\rho L}
\end{gathered}
$$

while we still have $i_{t}^{*}=-u_{t}$. We see this time that $i_{t}^{*}$ and $E_{t} \pi_{t+1}$ are correlated, so that $E_{t} \pi_{t+1}$ can play, at least partly, the role of a surrogate for $u_{t}$.

To further interpret the coefficient $\gamma$ in (53), let us separate two cases. First, in the case where $\rho=1$, expected inflation and the innovation $u_{t}$ are statistically equivalent, and we have:

$$
i_{t}^{*}=-u_{t}=E_{t} \pi_{t+1}
$$

so that quite naturally $\gamma=1$.

Now if $\rho<1, E_{t} \pi_{t+1}$ contains two terms (equation 56). The first one, $-\rho u_{t}$, is collinear to $u_{t}$. If there was only this term, the coefficient $\gamma$ would be equal to $1 / \rho$. But, because of the second term $\rho(1-\rho) u_{t-1} /(1-\rho L)$, an increase in $\gamma$ creates some inefficient "noise", so that in the end the actual coefficient $\gamma$ is between 0 and $1 / \rho$ (formula 53).

We can compute the value of the expected utility (formula 45) corresponding to this interest rate rule:

$$
E\left(\Delta_{t}\right)=-\frac{V}{2}-1
$$


We can also compute the expected utility corresponding to the rule found in proposition 3 , and we find:

$$
E\left(\Delta_{t}\right)=-1
$$

We see that, in view of (55), unless $\rho=1$ the rule using expected inflation will never do as well as the rule using the shocks directly.

\section{$7 \quad$ The interest rate rule under staggered prices}

We shall now study the optimal rule when prices are staggered ${ }^{10}$. The underlying idea (Calvo, 1983) is that in each period every price contract has a probability $\phi$ of being maintained, and a probability $1-\phi$ of being cancelled, in which case it is renegotiated on the basis of the latest information. The actual price is given, up to an unimportant constant, by the following weighted average:

$$
p_{t}=(1-\phi) \sum_{j=0}^{\infty} \phi^{j} E_{t-j} p_{t}^{*}
$$

These contracts have an average duration of $\phi /(1-\phi)$. We see that it is a quite flexible formulation, ranging from full flexibility $(\phi=0)$ to full rigidity $(\phi=1)$.

\subsection{The optimal rule}

We continue with the case $\sigma=1$, so that:

$$
p_{t}^{*}=-z_{t}
$$

Combining (60) and (61), we find that $p_{t}$ is equal to:

$$
p_{t}=-(1-\phi) \sum_{j=0}^{\infty} \phi^{j} E_{t-j} z_{t}
$$

We shall now characterize the optimal interest rate rule in the case where the interest rate is a function of current inflation.

\footnotetext{
${ }^{10}$ We use a variant of the famous Calvo (1983) contract. That variant was developed in microfounded models in Bénassy (2002a, 2003a,b), to which the reader is referred. Similar contracts have been proposed by Devereux and Yetman (2003) and Mankiw and Reis (2002).
} 
Proposition 6: Assume that the interest rate rule is function of current inflation:

$$
1+i_{t}=A \exp \left(\gamma \pi_{t}\right)=A \exp \left[\gamma\left(p_{t}-p_{t-1}\right)\right]
$$

then this rule is characterized by:

$$
\gamma=\frac{\phi(1+\rho)}{2(1-\phi)}
$$

Proof: Appendix 5.

We see this time that we have a more balanced view than in propositions 4 and 5 , since, depending on the values of $\phi$ and $\rho$, the coefficient $\gamma$ may be greater or smaller than 1 , so that the Taylor principle holds sometimes, but not as a general rule.

\subsection{An interpretation}

As before we shall now compute both the optimal response of interest rates to shocks, and the value of inflation as a function of shocks:

The optimal response of interest rates is (cf. formula 26 with $\sigma=1$ ):

$$
i_{t}^{*}=-z_{t}-p_{t}
$$

Now:

$$
z_{t}=\frac{u_{t}}{1-\rho L} \quad p_{t}=-\frac{(1-\phi) u_{t}}{(1-\rho L)(1-\phi \rho L)}
$$

So the optimal response is:

$$
i_{t}^{*}=-\frac{u_{t}}{1-\rho L}+\frac{(1-\phi) u_{t}}{(1-\rho L)(1-\phi \rho L)}=\frac{-\phi u_{t}}{1-\phi \rho L}
$$

We see that this time the interest rate should respond to a weighted average of past innovations in the technology. Let us now compute the value of inflation:

$$
\pi_{t}=(1-L) p_{t}=-\frac{(1-\phi)(1-L) u_{t}}{(1-\rho L)(1-\phi \rho L)}
$$

We see that, if $\rho=1, \pi_{t}$ and $i_{t}^{*}$ are collinear: $i_{t}^{*}=\phi \pi_{t} /(1-\phi)$, so that $\pi_{t}$ is a perfect surrogate for $i_{t}^{*}$, and therefore:

$$
\gamma=\frac{\phi}{1-\phi}
$$


which is what formula (64) tells us for $\rho=1$.

Now if $\rho<1$, one can again decompose $\pi_{t}$ as the sum of a term proportional to $i_{t}^{*}$, and one term orthogonal to it (noise). This computation is easy, but a bit clumsy, and is therefore omitted.

\section{Conclusions}

We constructed in this article a dynamic stochastic model for which it was possible to compute simple explicit solutions for optimal interest rate rules. We paid particular attention to the optimal reaction of nominal interest rates to inflation, and notably whether the elasticity of this reaction function should be greater than one (the Taylor principle).

We characterized this elasticity as a function of various underlying factors, and found that it could be smaller than one as well as greater, so that the Taylor principle does not hold in general.

We also saw on some examples that a rule using inflation as a surrogate for shocks usually does not perform as well as the rule using the original shocks. Therefore it would be more efficient to base interest rate policy directly on the information about the shocks, if it were available, of course.

In order to obtain explicit solutions the model presented here has been voluntarily streamlined. In particular some traditional transmission mechanisms are absent. Their inclusion would most likely necessitate the use of numerical simulations, but it is conjectured that this would not change the central message of this article. 


\section{References}

[1] Abel, Andrew B. (1987), "Optimal monetary growth", Journal of Monetary Economics, vol. 19, pp 437-450.

[2] Bénassy, Jean-Pascal (2002a), The Macroeconomics of Imperfect Competition and Nonclearing Markets: A Dynamic General Equilibrium Approach, Cambridge, Massachusetts: M.I.T. Press.

[3] Bénassy, Jean-Pascal (2002b), "Interest rate rules and price determinacy in a non Ricardian world", CEPREMAP, Paris, forthcoming in Review of Economic Dynamics.

[4] Bénassy, Jean-Pascal (2003a), "Staggered contracts and persistence: microeconomic foundations and macroeconomic dynamics", Louvain Economic Review, vol. 69, pp 125-144.

[5] Bénassy, Jean-Pascal (2003b), "Output and inflation dynamics under price and wage staggering: analytical results", Annales d'Economie et de Statistique, $\mathrm{n}^{\circ}$ 69, pp 1-30.

[6] Bullard, James and Kaushik Mitra (2002), "Learning about monetary policy rules", Journal of Monetary Economics, vol. 49, pp 1105-1129.

[7] Calvo, Guillermo (1983), "Staggered prices in a utility-maximizing framework", Journal of Monetary Economics, vol. 12, pp 383-398.

[8] Clarida, Richard, Jordi Gali and Mark Gertler (1999), "The science of monetary policy: a new Keynesian perspective", Journal of Economic Literature, vol. 38, pp 1661-1707.

[9] Devereux, Michael B. and James Yetman (2003), "Predetermined prices and the persistent effects of money on output", Journal of Money, Credit and Banking, vol. 35, pp 729-741.

[10] Erceg, Christopher J., Dale W. Henderson and Andrew T. Levin (2000), "Optimal monetary policy with staggered wage and price contracts", Journal of Monetary Economics, vol. 46, pp 281-313.

[11] Evans, George and Seppo Honkapohja (2003), "Expectations and the stability problem for optimal monetary policies", Review of Economic Studies, vol. 70, pp 807-824. 
[12] Friedman, Milton (1969), "The optimum quantity of money", in M. Friedman (ed), The Optimum Quantity of Money and Other Essays. London: Macmillan.

[13] Gray, Jo-Anna (1976), "Wage indexation: a macroeconomic approach", Journal of Monetary Economics, vol. 2, pp 221-235.

[14] Henderson, Dale W. and Jinill Kim (2001), "The choice of a monetary policy reaction function in a simple optimizing model", in A. Leijonhufvud (ed), Monetary Theory and Policy Experience, London: Macmillan.

[15] King, Robert G. and Alexander L. Wolman (1999), "What should the monetary authority do when prices are sticky", in J.B. Taylor (ed) Monetary Policy Rules, Chicago, University of Chicago Press.

[16] Mankiw, N. Gregory and Ricardo Reis (2002), "Sticky information versus sticky prices: a proposal to replace the new-Keynesian Phillips curve", Quarterly Journal of Economics, vol. 117 pp 1295-1328.

[17] Rotemberg, Julio J. and Michael Woodford (1997), "An optimization based econometric framework for the evaluation of monetary policy", NBER Macroeconomics Annual, vol. 12, pp 297-346.

[18] Rotemberg, Julio J. and Michael Woodford (1999), "Interest rate rules in an estimated sticky price model", in J.B. Taylor (ed) Monetary Policy Rules, Chicago: University of Chicago Press.

[19] Samuelson, Paul A. (1958), "An exact consumption-loan model of interest with or without the social contrivance of money", Journal of Political Economy, vol. 66, pp 467-482.

[20] Samuelson, Paul A. (1967), "A turnpike refutation of the golden rule in a welfare-maximizing many-year plan", in K. Shell (ed), Essays on the Theory of Optimal Economic Growth, Cambridge: M.I.T. Press.

[21] Samuelson, Paul A. (1968), "The two-part golden rule deduced as the asymptotic turnpike of catenary motions", Western Economic Journal, vol. 6 , pp 85-89.

[22] Svensson, Lars E. O. (1997), "Inflation forecast targeting: implementing and monitoring inflation targets", European Economic Review, vol. 41, pp 1111-1146. 
[23] Svensson, Lars E. O. (1999), "Inflation targeting as a monetary policy rule", Journal of Monetary Economics, vol. 43, pp 607-654.

[24] Taylor, John B. (1993), "Discretion versus policy rules in practice", Carnegie-Rochester Series on Public Policy, vol 39, pp 195-214.

[25] Taylor, John B. (1998), "Monetary policy and the long boom", Federal Reserve Bank of Saint-Louis Review, vol 80, n 6, pp 3-11.

[26] Woodford, Michael (2003), Interest and Prices: Foundations of a Theory of Monetary Policy, Princeton and Oxford: Princeton University Press. 


\section{Appendix 1}

\section{Walrasian Price Dynamics}

We shall compute the dynamics of the Walrasian price for the following process for $z_{t}$ :

$$
z_{t}=\frac{u_{t}}{1-\rho L}
$$

where $u_{t}$ is normal and i.i.d. Let us recall the basic equation:

$$
\frac{1}{P_{t}^{*}}=Z_{t} \Omega^{-\sigma} E_{t}\left(\frac{1}{P_{t+1}^{*}}\right)^{1-\sigma}
$$

Loglinearizing it and omitting constants we obtain:

$$
p_{t}^{*}=\frac{-z_{t}}{1-(1-\sigma) L^{-1}}=\frac{-u_{t}}{(1-\rho L)\left[1-(1-\sigma) L^{-1}\right]}
$$

We make the usual decomposition:

$$
\begin{gathered}
\frac{1}{(1-\rho L)\left[1-(1-\sigma) L^{-1}\right]}=\frac{\mu}{1-\rho L}+\frac{\mu}{1-(1-\sigma) L^{-1}}-\mu \\
\mu=\frac{1}{1-(1-\sigma) \rho}
\end{gathered}
$$

Consequently we have, up to irrelevant constants:

$$
p_{t}^{*}=-\mu \frac{u_{t}}{1-\rho L}=-\mu z_{t}
$$

\section{Appendix 2}

\section{Preset Wages}

We shall investigate here a different nominal rigidity, preset wages, and assume that the preset wage is equal to the expected value of the Walrasian wage (in logarithms), i.e.:

$$
w_{t}=E_{t-1} w_{t}^{*}
$$


where $w_{t}=\log W_{t}, w_{t}^{*}=\log W_{t}^{*}, W_{t}^{*}=Z_{t} P_{t}^{*}$, and $P_{t}^{*}$ is the solution of equation (16). We note that, since the Walrasian wage $W_{t}^{*}$ does not depend on the interest rate, the preset wage does not depend on it either.

\section{Equilibrium conditions}

Since the wage is preset, equation (12) does not hold anymore, but the other conditions are still valid:

$$
\begin{gathered}
\alpha C_{1 t}^{-\sigma}=\left(1+i_{t}\right) P_{t} \Omega^{-\sigma} E_{t}\left(\frac{1}{P_{t+1}}\right)^{1-\sigma} \\
C_{2 t}=\frac{\Omega}{P_{t}} \\
\frac{W_{t}}{P_{t}}=Z_{t}
\end{gathered}
$$

\section{The optimal interest rule}

Proposition 7: Under preset wages the optimal interest rate rule is:

$$
\frac{1}{1+i_{t}}=\min \left[1, W_{t} \Omega^{-\sigma} E_{t}\left(\frac{1}{P_{t+1}}\right)^{1-\sigma}\right]
$$

Proof: From formulas (77) and (79):

$$
C_{1 t}=\left[\frac{1+i_{t}}{\alpha Z_{t}} W_{t} \Omega^{-\sigma} E_{t}\left(\frac{1}{P_{t+1}}\right)^{1-\sigma}\right]^{-1 / \sigma}
$$

We have to maximize in $i_{t}$ for all values of the shocks:

$$
\alpha \frac{C_{1 t}^{1-\sigma}}{1-\sigma}-\frac{C_{1 t}}{Z_{t}}
$$

where $C_{1 t}$ is given by (81). Taking $C_{1 t}$ as an intermediate maximization variable, we find:

$$
C_{1 t}=\left(\frac{1}{\alpha Z_{t}}\right)^{-1 / \sigma}
$$

Equating the two values (81) and (83), and taking into account the fact that $i_{t}$ must be positive, we find (80).

Q.E.D. 


\section{Interest rate rule and shocks}

Let us now express the interest rate rule as a function of shocks only.

Proposition 8: Under preset wages the optimal interest rate rule is:

$$
i_{t}=-\frac{(1-\sigma) \rho}{1-(1-\sigma) \rho} u_{t}
$$

Proof: Formula (80) yields in logarithms:

$$
i_{t}=-w_{t}+(1-\sigma) E_{t} p_{t+1}
$$

Now:

$$
\begin{gathered}
w_{t}=E_{t-1} w_{t}^{*}=E_{t-1}\left(p_{t}^{*}+z_{t}\right)=-\mu E_{t-1} z_{t}+E_{t-1} z_{t} \\
p_{t+1}=w_{t+1}-z_{t+1}=-\mu E_{t} z_{t+1}+E_{t} z_{t+1}-z_{t+1} \\
E_{t} p_{t+1}=-\mu E_{t} z_{t+1}
\end{gathered}
$$

Combining (85), (86) and (88), we obtain:

$$
\begin{aligned}
& i_{t}=\mu E_{t-1} z_{t}-E_{t-1} z_{t}-(1-\sigma) \mu E_{t} z_{t+1} \\
& =\mu \frac{\rho u_{t-1}}{1-\rho L}-\frac{\rho u_{t-1}}{1-\rho L}-(1-\sigma) \mu \frac{\rho u_{t}}{1-\rho L}
\end{aligned}
$$

and, simplifying, formula (84).

Q.E.D.

We see that under preset wages the elasticity of reaction to the technology shock (formula 84) is substantially different from that under preset prices (formula 32).

\section{Appendix 3}

\section{Proof of Proposition 4}

Finding the optimal rule consists in finding the optimal values for the two parameters $\gamma$ and $A$. So, combining (45) and (46), one will maximize with respect to these two parameters the following quantity: 


$$
E\left(\Delta_{t}\right)=-\log A-E\left[\gamma\left(p_{t}-p_{t-1}\right)\right]-\frac{1}{A} E \exp \left[-z_{t}-p_{t}-\gamma\left(p_{t}-p_{t-1}\right)\right]
$$

Given relation (39) this becomes:

$$
\begin{gathered}
E\left(\Delta_{t}\right)=-\log A-E\left[\gamma\left(E_{t-1} z_{t}-E_{t-2} z_{t-1}\right)\right] \\
-\frac{1}{A} \exp \left[-z_{t}+E_{t-1} z_{t}+\gamma\left(E_{t-1} z_{t}-E_{t-2} z_{t-1}\right)\right]
\end{gathered}
$$

Because $z_{t}$ is normal, this simplifies to:

$$
E\left(\Delta_{t}\right)=-\log A-\frac{1}{A} \exp \left(\frac{V}{2}\right)
$$

where $V$ is the variance of the last term into brackets in expression (91). Now we have:

$$
E_{t-1} z_{t}=\frac{\rho u_{t-1}}{1-\rho L} \quad E_{t-2} z_{t-1}=\frac{\rho u_{t-2}}{1-\rho L}
$$

The term in brackets in (91) is equal to:

$$
\begin{gathered}
\frac{u_{t}}{1-\rho L}-\frac{\rho u_{t-1}}{1-\rho L}-\frac{\gamma \rho u_{t-1}}{1-\rho L}+\frac{\gamma \rho u_{t-2}}{1-\rho L} \\
=u_{t}-\gamma \rho u_{t-1}+\frac{\gamma \rho(1-\rho)}{1-\rho L} u_{t-2}
\end{gathered}
$$

and its variance $V$ is therefore equal to:

$$
V=1+\gamma^{2} \rho^{2}+\frac{\gamma^{2} \rho^{2}(1-\rho)^{2}}{1-\rho^{2}}=1+\frac{2 \gamma^{2} \rho^{2}}{1+\rho}
$$

We see that minimum variance is reached for $\gamma=0$. The corresponding variance is $V=1$.

\section{Appendix 4}

\section{Proof of Proposition 5}

Combining (45) and (52), we will maximize with respect to $\gamma$ and $A$ : 


$$
E\left(\Delta_{t}\right)=-\log A-E\left[\gamma E_{t}\left(p_{t+1}-p_{t}\right)\right]-\frac{1}{A} E \exp \left[-z_{t}-p_{t}-\gamma E_{t}\left(p_{t+1}-p_{t}\right)\right]
$$

Given relation (39) this becomes:

$$
\begin{gathered}
E\left(\Delta_{t}\right)=-\log A-E\left[\gamma\left(E_{t} z_{t+1}-E_{t-1} z_{t}\right)\right] \\
-\frac{1}{A} \exp \left[-z_{t}+E_{t-1} z_{t}+\gamma\left(E_{t} z_{t+1}-E_{t-1} z_{t}\right)\right]
\end{gathered}
$$

Again this simplifies as formula (92):

$$
E\left(\Delta_{t}\right)=-\log A-\frac{1}{A} \exp \left(\frac{V}{2}\right)
$$

where $V$ is now the variance of the last term into brackets in (97). We have:

$$
E_{t-1} z_{t}=\frac{\rho u_{t-1}}{1-\rho L} \quad E_{t} z_{t+1}=\frac{\rho u_{t}}{1-\rho L}
$$

The last term in brackets in (97) is equal to:

$$
\begin{gathered}
\frac{u_{t}}{1-\rho L}-\frac{\rho u_{t-1}}{1-\rho L}-\frac{\gamma \rho u_{t}}{1-\rho L}+\frac{\gamma \rho u_{t-1}}{1-\rho L} \\
=\frac{1-\gamma \rho-\rho(1-\gamma) L}{1-\rho L} u_{t}=(1-\gamma \rho) u_{t}+\frac{\gamma \rho(1-\rho)}{1-\rho L} u_{t-1}
\end{gathered}
$$

so its variance $V$ is equal to:

$$
V=(1-\gamma \rho)^{2}+\frac{\gamma^{2} \rho^{2}(1-\rho)^{2}}{1-\rho^{2}}=(1-\gamma \rho)^{2}+\frac{\gamma^{2} \rho^{2}(1-\rho)}{1+\rho}
$$

Minimization with respect to $\gamma$ yields:

$$
\gamma=\frac{1+\rho}{2 \rho}
$$

Inserting (102) into (101) we obtain the resulting variance:

$$
V=\left(1-\frac{1+\rho}{2 \rho}\right)^{2}+\left(\frac{1+\rho}{2 \rho}\right)^{2} \frac{1-\rho}{1+\rho}=\frac{1-\rho}{2}
$$

Maximizing expected utility (98) with respect to the constant term $A$ yields: 


$$
A=\exp \left(\frac{V}{2}\right)
$$

so that the value of the expected utility is:

$$
E\left(\Delta_{t}\right)=-\frac{V}{2}-1
$$

\section{Appendix 5}

\section{Proof of Proposition 6}

From (31) and (62) the price is equal to:

$$
\begin{gathered}
p_{t}=-(1-\phi) \sum_{j=0}^{\infty} \phi^{j} E_{t-j} z_{t}=-(1-\phi) \sum_{j=0}^{\infty} \frac{\phi^{j} \rho^{j} u_{t-j}}{1-\rho L} \\
=-\frac{(1-\phi) u_{t}}{(1-\rho L)(1-\phi \rho L)}
\end{gathered}
$$

We want to minimize:

$$
\begin{gathered}
E \exp \left[-z_{t}-p_{t}-\gamma\left(p_{t}-p_{t-1}\right)\right] \\
=E \exp \left[-\frac{u_{t}}{1-\rho L}+\frac{(1-\phi) u_{t}}{(1-\rho L)(1-\phi \rho L)}+\frac{\gamma(1-\phi)(1-L) u_{t}}{(1-\rho L)(1-\phi \rho L)}\right] \\
=E \exp \left[\frac{-\phi u_{t}}{1-\phi \rho L}+\frac{\gamma(1-\phi)(1-L) u_{t}}{(1-\rho L)(1-\phi \rho L)}\right]
\end{gathered}
$$

Now:

$$
\frac{(1-\phi)(1-L)}{(1-\rho L)(1-\phi \rho L)}=\frac{1}{\rho}\left[\frac{1-\phi \rho}{1-\phi \rho L}-\frac{1-\rho}{1-\rho L}\right]
$$

so the expression in (107) is equal to:

$$
\begin{aligned}
& E \exp \left[\frac{-\phi u_{t}}{1-\phi \rho L}+\left(\frac{1-\phi \rho}{1-\phi \rho L}-\frac{1-\rho}{1-\rho L}\right) \frac{\gamma u_{t}}{\rho}\right] \\
& =E \exp \left[\frac{\gamma(1-\phi \rho)-\phi \rho}{\rho(1-\phi \rho L)} u_{t}-\frac{\gamma(1-\rho)}{\rho(1-\rho L)} u_{t}\right]
\end{aligned}
$$


We want to minimize the variance of the quantity in brackets. The term of order $j$ in the brackets in (109) is equal to:

$$
\frac{\gamma(1-\phi \rho)-\phi \rho}{\rho} \phi^{j} \rho^{j} u_{t-j}-\frac{\gamma(1-\rho)}{\rho} \rho^{j} u_{t-j}
$$

The variance of the term of order $j$ is, omitting the $\rho$ in the denominator:

$$
\begin{gathered}
{[\gamma(1-\phi \rho)-\phi \rho]^{2} \phi^{2 j} \rho^{2 j}+\gamma^{2}(1-\rho)^{2} \rho^{2 j}} \\
-2 \gamma(1-\rho)[\gamma(1-\phi \rho)-\phi \rho] \phi^{j} \rho^{2 j}
\end{gathered}
$$

Summing over all values of $j$ from zero to infinity we find the total variance:

$$
\frac{[\gamma(1-\phi \rho)-\phi \rho]^{2}}{1-\phi^{2} \rho^{2}}+\frac{\gamma^{2}(1-\rho)^{2}}{1-\rho^{2}}-\frac{2 \gamma(1-\rho)[\gamma(1-\phi \rho)-\phi \rho]}{1-\phi \rho^{2}}
$$

Differentiating with respect to $\gamma$ yields the first order condition:

$$
\frac{\gamma(1-\phi \rho)-\phi \rho}{1+\phi \rho}+\frac{\gamma(1-\rho)}{1+\rho}-\frac{(1-\rho)[2 \gamma(1-\phi \rho)-\phi \rho]}{1-\phi \rho^{2}}=0
$$

Let us factor the coefficient $\gamma$ :

$$
\gamma\left[\frac{1-\phi \rho}{1+\phi \rho}+\frac{1-\rho}{1+\rho}-\frac{2(1-\rho)(1-\phi \rho)}{1-\phi \rho^{2}}\right]=\phi \rho\left[\frac{1}{1+\phi \rho}-\frac{1-\rho}{1-\phi \rho^{2}}\right]
$$

Now:

$$
\begin{gathered}
\frac{1}{1+\phi \rho}-\frac{1-\rho}{1-\phi \rho^{2}}=\frac{\rho(1-\phi)}{(1+\phi \rho)\left(1-\phi \rho^{2}\right)} \\
\frac{1-\phi \rho}{1+\phi \rho}-\frac{(1-\rho)(1-\phi \rho)}{1-\phi \rho^{2}}=\frac{\rho(1-\phi \rho)(1-\phi)}{(1+\phi \rho)\left(1-\phi \rho^{2}\right)} \\
\frac{1-\rho}{1+\rho}-\frac{(1-\rho)(1-\phi \rho)}{1-\phi \rho^{2}}=\frac{\rho(1-\rho)(\phi-1)}{(1+\rho)\left(1-\phi \rho^{2}\right)}
\end{gathered}
$$

Combining the last four equations we obtain:

$$
\gamma\left[\frac{1-\phi \rho}{1+\phi \rho}-\frac{1-\rho}{1+\rho}\right]=\frac{\phi \rho}{1+\phi \rho}
$$

which simplifies as:

$$
\gamma=\frac{\phi(1+\rho)}{2(1-\phi)}
$$

